\title{
Pathways towards reverse logistics adoption in Indian educational institutes: a challenging factors analysis
}

\author{
K. Mathiyazhagan ${ }^{1}\left({ }^{(0)} \cdot\right.$ Srijit Krishnan $^{1} \cdot$ Uma Bharathi $^{2} \cdot$ Andrea Appolloni $^{3,4}$
}

Accepted: 13 November 2020

(c) Operational Research Society of India 2021

\begin{abstract}
Reverse logistics (RL) has been proven to have a positive effect on addressing the issue of effectively utilizing resources. India has a population of over one billion people with most of it dominated by youth. Developing RL strategies and exposing it to students will encourage them to find ways to manage the limited resources available in our country. This study is focused on identifying the challenges of RL implementation in education institutes in India and finding the inter-relationship among them. The most crucial barrier to RL implementation in educational institutes is also sought in the process. We initially review the RL practices in the Indian sub-continent to examine the challenges of effectively implementing RL. We then identify the challenges of RL based on literature and discussions with experts from the education industry. The experts selected for this study include administrators from schools and universities in Kerala, India (South India). A survey was conducted in two phases. The Fuzzy-DEMATEL technique was applied to determine the inter-relationship between the challenges and obtain the causal diagram. Initially, 45 challenges were identified. Based on responses from experts from phase one of the survey, it was narrowed down to 29 crucial challenges. A pairwise comparison among the challenges was then done by experts in the education field. Finally, on the application of Fuzzy-DEMATEL, a causal diagram was generated to indicate the extent of influence of the RL challenges. Our findings indicate that educational institutions are faced with lack of awareness about reverse logistic, lack of responsibilities about environment, resistance to change, lack of supplies on supplier end, lack of knowledge, and no proper outlet for disposal in managing RL operations in educational institutes. The challenges identified in our study is unique to the Indian sub-continent and provides a result based on the current scenario of RL implementation in Indian educational institutes. The findings from our study indicate a unique perspective of RL implementation challenges. We analyzed 29 challenges to obtain our findings. Furthermore, we use Fuzzy-DEMATEL as our analysis tool to facilitate finding results. We present this as the uniqueness of our study from the available literature.
\end{abstract}

Extended author information available on the last page of the article 
Keywords Challenging factors · Reverse logistics · Implementation · India · Educational institutes $\cdot$ Fuzzy-DEMATEL

\section{Introduction}

Environment protection is one of the main issues on which various worldwide conferences, discussions, and summits are being organized. Sharma et al. [1] mentioned that organizations are actively taking part in the Go Green Movement and now they are more eco-conscious because of government regulations and continual awareness from social media. It is one of the driving sources to think and adopt green purchasing and green manufacturing. Also, organizations and industries are constantly being forced by the government to adopt eco-friendly methods and strategies during different stages of the supply chain. Some of the examples of this approach are how companies in different fields, such as consumer goods, technology, and manufacturing are making commitments on going green by following R-R-R strategy and doing it as well. The most recent example of this is Adidas using plastic waste from oceans to develop their new line of shoes 'Parley' on a global level. This initiative is one of the best examples of reverse logistics by one of the global sports companies. Also, the government itself is promoting reverse supply chain activities by purchasing eco-products. RL is a contemporary approach in the age of minimum waste, optimal resource utilization, effective disposal, high efficiency, and profit maximization [2]. Reverse supply chain limits waste within the production system or organization. The reader may encounter terms like return logistics, reverse distribution or return logistics in other literature, however, all referring to reverse logistics [3].

This study focuses on determining the challenging factors (CFs) in implementation of RL in educational institutes in the environmental aspect. Based on the literature reviewed, $29 \mathrm{CFs}$ were considered for this study under four categories namely-Personal Factor (PF), Product Oriented (PO), Administration (AD) and Financial Factor (FF). Educational institutes can be one of the most influential places for taking green initiatives such as green logistics as this would bring some sense of awareness about the environment in the millennial generation which is need of the twenty-first century. This also leads to government working more at the policy level in this area.

Our study is presented based on the study conducted in Indian educational institutes. We initially update the status of RL adoption based on a review of the literature. As a result, we identified 45 CFs. We then narrow down these CFs to the critical 29 CFs. We apply fuzzy-DEMATEL to identify the prominent challenges that affect RL implementation in the institutes where we conducted our study. DEMATEL alone is a powerful tool to assess various qualitative dimensions. However, we consider the vagueness of questionnaire responses by applying fuzzy-DEMATEL. The CFs presented in our study are actual challenges faced by institutes. The process of narrowing down our CFs from 45 to $29 \mathrm{CFs}$, the responses, and the implications of the findings of our study was facilitated by experts in educational institutes. We focus our study of challenges of RL adoption to the educational sector in the Indian context, and we do this with the application of an MCDM tool to provide us with 
insights that would be useful to not just the research community, but also RL adopters in the educational space.

\subsection{Objectives of the study}

1. Review the status and identify the list of CFs for the adoption of RL from the literature and discussions with educational institutes located in the Indian subcontinent.

2. Analyze and identify the influential critical factors with the help of fuzzy-DEMATEL approach through experts' opinion.

This paper discusses the importance of RL and the objective of this study is introduced in this section. Section 2 presents the literature reviewed which forms the basis of identification of challenges. Section 3 presents the opportunities that RL has in Indian educational institutes and benefits of its adoption. This section also presents the result of reviewing the literature, that is, identification of 45 challenges of RL adoption in educational institutes. Though 45 challenges were initially identified, only 29 of the crucial challenges based on the experts' response from a questionnaire survey have been listed in this section. Section 4 gives a brief description of the problem environment of RL implementation in Indian educational institutes. Section 5 presents the methodology followed (fuzzy-DEMATEL) to analyze the data we received from the respondents for the survey questionnaire developed. Section 5 gives an overview of the targeted experts and how data collection through a questionnaire was conducted in two phases. The result from the analysis of data is then discussed in Sect. 6. Section 7 summarizes the study along with the implication this study has on managers or decision-makers of educational institutes. Their recommendations and suggestions are presented. This section also elaborates on the limitations and scope of this study.

\section{Research background: RL in education institutes}

Reverse logistics is the process of planning, implementing and controlling the efficient, cost-effective flow of raw materials, in-process inventory, finished goods and related information from the point of consumption to the point of origin to recapture value, or proper disposal $[4,5]$. Under low admission pressure, most institutes are struggling for endurance. Therefore, cost reduction strategies are being made by the human resource department instead of green purchasing and RL green purchasing. RL will not only allow cost reduction but will also allow greater competitive advantage and would improve brand image. It would educate the future generation to be concern about the environment and adopt green purchasing and green manufacturing. Corless and Ward [6] presented a case study on brown university with a tagline of "Can Brown be Green?" They highlighted that educational institutes can enrich education by teaching them to reduce the harmful impact on the environment, resource consumption and cost of operation to day to day life. There are 
numerous reasons to adopt RL in educational institutes but due to the following challenges, it is difficult to implement RL. Pandey and Govind [7] confirmed that lack of awareness is the major reason causing rapidly increasing e-waste in India. If it is not sensitized, it can cause hazardous results and health problems for future generations. Prakash and Barua [8] indicated that RL practices are in the embryonic stage in India. Because of weak legislation, price-sensitive market, lack of societal pressure and environmental issues, RL is difficult to implement in developing countries like India. Wooi [9] studied the barriers in the adoption of GSCM in SMEs in Malaysia. They concluded that the lack of resource is the key barrier in SMEs in Malaysia. They also mentioned that firms which have business-oriented mindset are more interested in applying green supply chain management (GSCM) concept in their firms rather than the firms which have family-oriented. Govindan et al. (2014) [10] presented a framework for barriers in implementing GSCM in industries and ranked technology the most important barrier. Knowledge, outsourcing and financial barriers come next to this. Sharma et al. (2011) [11] identified three barriers namely, financial constraints, legal issues, and lack of awareness for the adoption of RL in Indian industries. Pohlen and Farris [12] identified three other barriers for RL adoption in the plastic recycling industry perspective such as RL is inefficient due to differing product characteristics, labour-intensive handling, and low-density shipments. Lau and Wang [13] analyzed the case of RL in the electronic industry in China and figured out that lack of enforceable laws, regulations or directives to motivate manufacturers, no economic support, and tax policies are major barriers in implementing RL in the Chinese electronics industry. Next, there is little economic control by the state, such as severe penalties or heavy pollution tax, to prevent companies from violating environment protection directives. Rogers and Tibben-Lembke [14] mentioned that a general lack of recognition of the importance of RL and lack of information system resource are important two obstacles for RL. According to Kannan, Pokharel, and Sasi Kumar [15] uncertainty in the number of products received and timing is the major challenge associated with RL. Challenges can be overcome if some factual and versatile motivations are projected and ranked according to their influence.

Govindan et al. [10] confirmed that the adoption of green supply chain activities requires support and coordination from all the persons in the hierarchy from the top level to bottom level. Convincing senior management and making them aware of long term economic and environmental benefits of RL should be the primary objective $[13,16]$. The contribution should be from all the departments to boost the RL [13]. Pohlen and Farris [12] figured out that RL cost can be reduced by specialization and consolidation. They also included that if the density of recycled product can be increased and the market can be extended for recycled products then price can be stabilized [13]. Active recycling centers for recycling and disposal can solve this problem up to an extent. Similarly Spekmand et al. [17] mentioned that close coordination between the linkages plays a significant role in profit maximization and cost reduction in the supply chain (SC). More pressure for sustainability by businesses is the driving force which is helping to adopt GSCM these days [18]. Hassle-free and effective response of RL activities should be facilitated [16]. Outsourcing is an intelligent option in this competitive era. It can help the active response of RL activities 
[19]. Kannan et al. [15] mentioned that adequate logistics network is required for effective implementation of RL activities such as collection, storage, inspection, recycling, remanufacturing, repairing, distribution, disposal, etc. Sarkis et al. (2010) [20] studied that society is the most important factor in the implementation of environment-oriented RL practices. Society should be more aware of environmental issues and should compel the firms to adopt RL practices to save the environment. Firms or businesses should take a close look in each area and find out where and how RL concept can be utilized. It is high time for industries and service sectors to optimize their one way supply chain to closed-loop supply chains and accept the RL challenge to give a better tomorrow to the next generation.

From the review of literature, it was identified that a similar methodology has been used in various research work for the analysis of barriers/ challenges of RL implementation in other industry sectors using MCDM techniques. One such research identifies and analyzes the RL barriers common to various sectors which were further analyzed for priority barriers in the electrical-electronic industry. Bouzon et al. [21] concluded that a major obstacle of RL adoption was the uncertainty related to economic issues and the financial burden of the tax. Jindal and Sangwan [22] identified 16 barriers of adopting RL common to all sectors in India. An interrelationship analysis of the barriers reveals that the implementation of RL practice in Indian industries should be initiated and encouraged by the government. Prakash et al. [23] analyzed the barriers of RL implementation in the electronics industry in India. They identified that lack of coordination with 3PL providers, lack of monitoring systems and customer perceptions are major barriers to RL implementation. Prakash et al. [23] conducted extensive work to identify 38 barriers to RL adoption and offer 20 solutions for which analysis using fuzzy AHP-TOPSIS for ranking has been performed. In their study, they identified that the legal barriers are the dominant barriers to RL implementation. Samarasinghe [24] studied challenges of RL adoption in Sri Lanka and revealed that managers have a laid back attitude towards RL adoption. This challenge could be a major one in many of the developing countries. It is therefore evident that several such research work has been done from various countries whereby RL challenges are identified and analyzed. However, there is still less work analyzing RL in education institutes.

The institutes from where the study was conducted generally followed a reverse physical distribution/ logistical channel such as the one illustrated in Fig. 1.

We illustrate a distribution channel similar to that observed generally in manufacturing facilities-Fig. 1. Meade and Sarkis [25] presented a similar lifecycle for a product in a manufacturing plant. This comes to show that this study, though focused on educational institutes, it may also show value to practitioners in other industries as well.

\section{Results of review background}

India has attained substantial i.e. 7.4\% annual growth in the economy. But it is still facing the challenge of resource scarcity [26]. USA and China have profound RL strategy and vision. But India can lose its competitive edge if systematic work is 


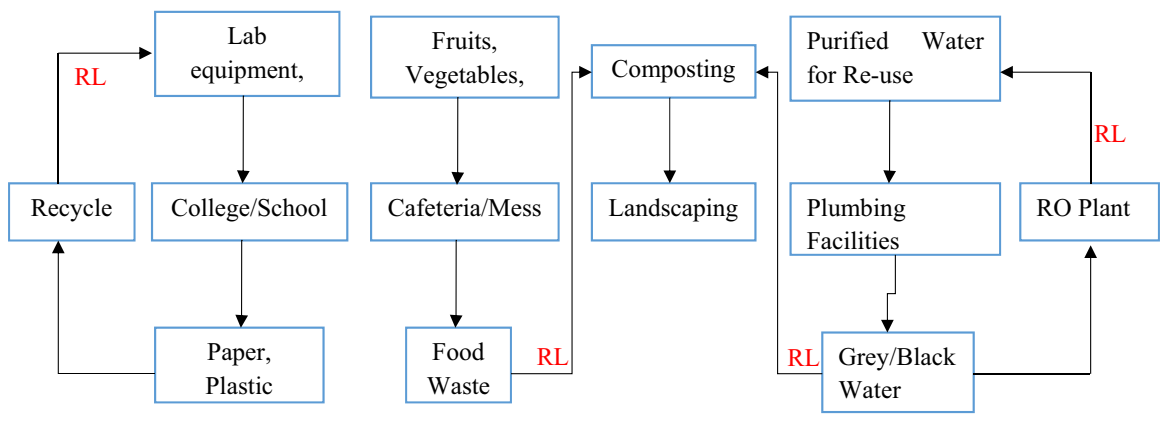

Fig. 1 Physical distribution indicating re-use of resources in a typical educational institute

not done in the required area of RL. So it is a critical time to apply this concept in every possible organization. RL has been practiced in many industries like appliances, construction, textile, medical, steel, aircraft, automobile, computers, paper, carpets, chemicals, electronics, etc. but very less work has been done in educational institutes and work that was done in the ' 90 s is not updated. This research emphasizes challenges and opportunities to apply RL concept in educational institutes are, young nurturing minds are the future of India. Some proactive measures taken for implementation of RL in educational institutes can lead to solving the challenge of resource scarcity, cost reduction, better environmental performance, competitive advantage, increase market share and nurturing young minds to their whole life and day to day work.

\subsection{Opportunities of RL in Indian educational institutes}

$\mathrm{RL}$ is the process of planning, implementing and controlling the effective, costeffective flow of materials from point of consumption to point of origin for the sole purpose of recapturing value [14]. Some research such as one by White [27] focused on opportunities of improvement in aspects of material handling in RL that include transport, inventory handling and distribution. BLANCHARD [28] recognized RL as an opportunity for effective differentiation and competitive advantage. RL is becoming the top management priority due to its potential value and the effect it has on the satisfaction of the customer. RL gives the adopters a great opportunity to understand customers and, maintaining a healthy relationship, their loyalty can be ensured [29]. An efficient and effective RL has tremendous potential in improving economic performance and relationship with the customers. Management of RL consumes a lot of resources during its maintenance and implementation and significant time and resource need to be committed [30]. The loyalty of a customer is a direct outcome of the quality service of the RL program. The satisfaction of the customer is the intermediary of apparent quality service and loyalty of the customer. $\mathrm{RL}$ is necessary for increasing the life of material and products. Papers, bottle, stationary items, furniture, water/RO water, food, projects models, PV cell, scrap item should be properly disposed of, all items e.g. electronic item should be sent back for 
recycling. Rogers and Tibben-Lembke [4] identified that book distributors typically have high returns (10-20\%). Very few books make it to the bestseller list. Projecting demand for others is difficult. RL has a positive effect on performance, defined by cost-effectiveness; processing effectiveness; and operating level effectiveness [29]. $[31,32]$ have indicated that RL has ultimate benefit of being able to 'clean out' the channel by way of removing obsolete or slow-moving items and hence make room for newer ones. A goods return handling system serves the ability to function as a profit center. Some types of items are capable of being remanufactured and sold again in the market [33]. Estee Lauder, the renowned manufacturer of cosmetics, illustrated reclamation of value. Their unsold products are sent back to the factory and are then resorted, repackaged, and resold at a higher margin [34]. An institution's management needs to keep a close eye on factors that could take away the potential profit, frustrate the customers and put a drain over the scarce resources of the firms $[14,35,36]$. So it is imperative for industries to effectively and efficiently handle the RL issues. Now institutions worldwide have started to realize the importance of RL and its potential benefits to gain efficiency and effectiveness in their operations. They have started to use RL as a value-added center and use their reverse process as a differentiator.

Practicing RL has a positive impact on the satisfaction of the society, competitive differentiation and profitability. RL in education institutions comes with its benefits. The most effective of these benefits is improved environmental sustainability. RL is an environmentally sustainable supply chain solution. By making the RL system efficient, a reduction in the burden on logistical assets and the environmental resources is required to keep the system running. For effective RL functioning, the key is to be able to utilize the forward logistics assets to support it. To do this, the returnable items may be collected at distribution points to allow transportation assets involved in forwarding deliveries pick these recyclable items when they would traditionally be left at the delivery points underutilized.

\subsection{Challenging factors for $R L$}

Personnel Factor (PF) Human beings have traits like emotions, social behaviour, culture, physical constraints, ethics values, thoughts, and feelings, etc.; some are in an acceptable limit, while some are beyond the acceptable limit. Some barriers are listed which completely depend on some common human behaviour.

Lack of awareness about reverse logistic (PF1): Lack of awareness about RL especially the environment, social issues, recycling processes, waste management, remanufacturing, social responsibilities, etc. acts as a fundamental barrier for implementation of RL.

Non-cooperative behaviour of faculties and staff (PF2): Cooperation is primitive for the success of any organization or relationship. Generally, people ignore the things and issues which do not give direct benefit to them.

Lack of responsibilities about the environment (PF3): Natural resources are free of cost and that is the main reason for the negligence of environment issues. A lot of programs and research are going on this emerging topic but all that will only be 
documented. Everyone will have to take individual responsibility for environmental protection.

Resistance to change (PF4): It is a very common human behaviour. Resistance to change is a critically important contributor to the failure of conceived efforts to initiate RL.

Lack of recycled supplies on retailer end (PF5): As per usual human behaviour retailer is concerned about profit maximization only. He shows the inefficiencies of a supplier to supply recycled or green products.

Lack of supplies on supplier end (PF6): Supplier is the heart of any supply chain, but due to lack of awareness, lack of concern about the environment, common human nature for more profit suppliers do not supply recycled products to the retailer. Performance of supplier affects the performance of the entire supply chain and RL. Therefore, this acts as an important barrier, especially in educational institutes.

Lack of knowledge (PF7): Most of the people are unaware of environmental consequences and future endangerment and crisis.

Product Oriented (PO) Decreased quality (PO1): Quality of recycled products is degraded but customer demands the same level of quality as the new product.

Easy availability of resources (e.g. paper) (PO2): In this age of competition everything is readily available. A minor delay in delivery of products can cause big profit loss. Due to easy availability, people don't take the pain to recycle or remanufacture the product which is a time taking process.

No proper outlet for disposal (PO3): India is still in the starting phase of application of green supply chain management concept. Very few outlets have been opened for automobile and electronics sector but not for daily need utility items. Still, a long path needs to be travelled.

Variety of products (PO4): Products received for recycling are not of the same quality. Some are in good condition, some in acceptable and some in a very bad condition which can't be recycled.

Administration (AD) Lack of management interest (AD1): Management is not interested in adopting new things which results in high investments and comparatively fewer returns.

Lack of fund for research and development (AD2): Facilities for research and development are very few. New technology, new setups with the least manufacturing or recycling cost per component need to be found out.

Less profit in starting phase (AD3): In profit maximization strategy, reducing the cost is the primary task without violating the institutional mission and vision, e.g. reducing electricity consumption by proper monitoring of the classrooms after every lecture. But RL concept will add extra initial investment, extra time for making proper strategies, extra manpower, etc. which will ultimately reduce the profit for a short term.

Time constraint (AD4): $\mathrm{RL}$ is a time-consuming issue which requires special planning, strategies, discussions, and step by step attention. 
Lack of institute's vision and mission towards effective utilization (AD5): Institute's vision and mission substantially affect the decisions taken by a company for adopting a new process or approach. In this competitive era, institutes do not want to compromise the brand image as the manufacture of the product after recycling or cannibalizing will not have the same product quality.

Fear of failure (AD6): RL requires a huge investment in the starting phase and yields profit only when supply is continuous and in large volume. Management is always worried if things do not happen as per plan.

Lack of future planning (AD7): Proper future planning leads to an innovative method and growth to an organization. But good and strong strategies need to be made for successful adoption of RL in an organization.

Lack of information flow (AD8): Systematic information should flow from top to bottom in the hierarchy. A small information gap or improper information leads to add extra cost to an organization. For example, wrong inventory data of desks and chairs can result in buying extra furniture.

Lack of environmental awareness events/ training/ workshop etc. (AD9): Very young, fresh and adaptable minds enter into educational institutes. Environment awareness events, training, workshop, seminars etc. are a good way to make them cautious about their surroundings.

Lack of knowledge for finding RL opportunities (AD10): Organizations find difficulty in finding opportunities for RL adoption.

Out of responsibility zone (AD11): Organizations generally believe that environmental protection is not their responsibility. Organization takes steps only when it is mandatory by government laws.

Financial Factor (FF) Lack of student's admissions (FF1): New institutes and colleges are opening with fast pace resulting in lesser admissions per institution and high competition.

High investment in starting phase (FF2): Technology for recycling, information flow, machine setup, manpower requirement, infrastructure all these essential things require a high initial investment.

Long payback period (FF3): High initial investment and less profit for short period lead to a long payback period.

Lack of system to monitor returns (FF4): Performance measurement matrix misalignment is a sign of inefficiency in the organization. Linking performance measurement matrix with RL activities can provide a successful and continuous implementation of RL activities.

Less economic value recovered from the end of life products (FF5): As explained earlier, huge initial investment, but fewer returns from the end of life products is also an important challenging factor.

Lack of infrastructural facilities (FF6): Non-availability of appropriate infrastructure like technology, process, skilled labour acts as an important barrier for adoption of RL activities.

Need for extra Human Resource (FF7): More skilled persons are required to carry out RL activities. 
Table 1 summarizes the above information with a brief description of each of the identified sub-criteria.

\section{Problem environment}

Educational institutes in India are developing an infrastructure based on student admissions. Student admissions are directly proportional to campus placement which mostly depends on the ability of students to meet new challenges, being flexible enough to change as per new technical advances. These qualities help the industries to gain competitive advantage. Applying green procurement and RL techniques to promote environmental initiatives and cost reduction is being encouraged by the industries. While the worldwide conferences, summits are being held on environment protection, this issue is expected to influence the entire Indian industry in a big way. The Indian educational institutes, therefore, should adopt a proactive approach to address the issues of RL. Educational institutes should be the live practical example of green practices for their students to make their contribution towards the environment.

Due to low admissions, Indian education institutes are under pressure to focus on cost reduction. Educational institutes are the lifeline of society, and the adoption of $\mathrm{RL}$ is the best way to make students more conscious and aware of the environment. However, due to various challenges, RL implementation is very complex in educational institutes. Through detailed literature and in discussion with academicians, 45 challenges have been identified and categorized based on the similarities of meaning and discussion experts. The most common barriers are identified through a questionnaire survey from different industrial sectors (for more details kindly refer Sect. 5.2).

\section{Research methodology}

We follow the research methodology illustrated-Fig. 2 . We initially conducted a thorough review of the current status of RL practices. Through the review, we identify the gaps in the literature. This resulted in defining the problem statements. Subsequently, RL practices were studied in various educational institutes, from which we were able to identify the initial 45 CFs of RL adoption in the educational sector. Based on experts' suggestions, we narrowed down our CFs to 29 crucial ones. These CFs were divided into 5 accordingly_-'Product', 'Financial', 'Administration', 'Government', 'Personnel'. Based on responses from data collected (Refer Sect. 5.2), we applied the fuzzy-DEMATEL technique to evaluate these crucial CFs. We then discuss our findings based on feedback from the same experts we referred to earlier.

This method of research study is a widely used methodology and is proven to be effective for qualitative scientific research. The basis of this study is the review of literature, from which we obtain the gaps in the study, and we address this gap through a structured methodology as shown in Fig. 2. 


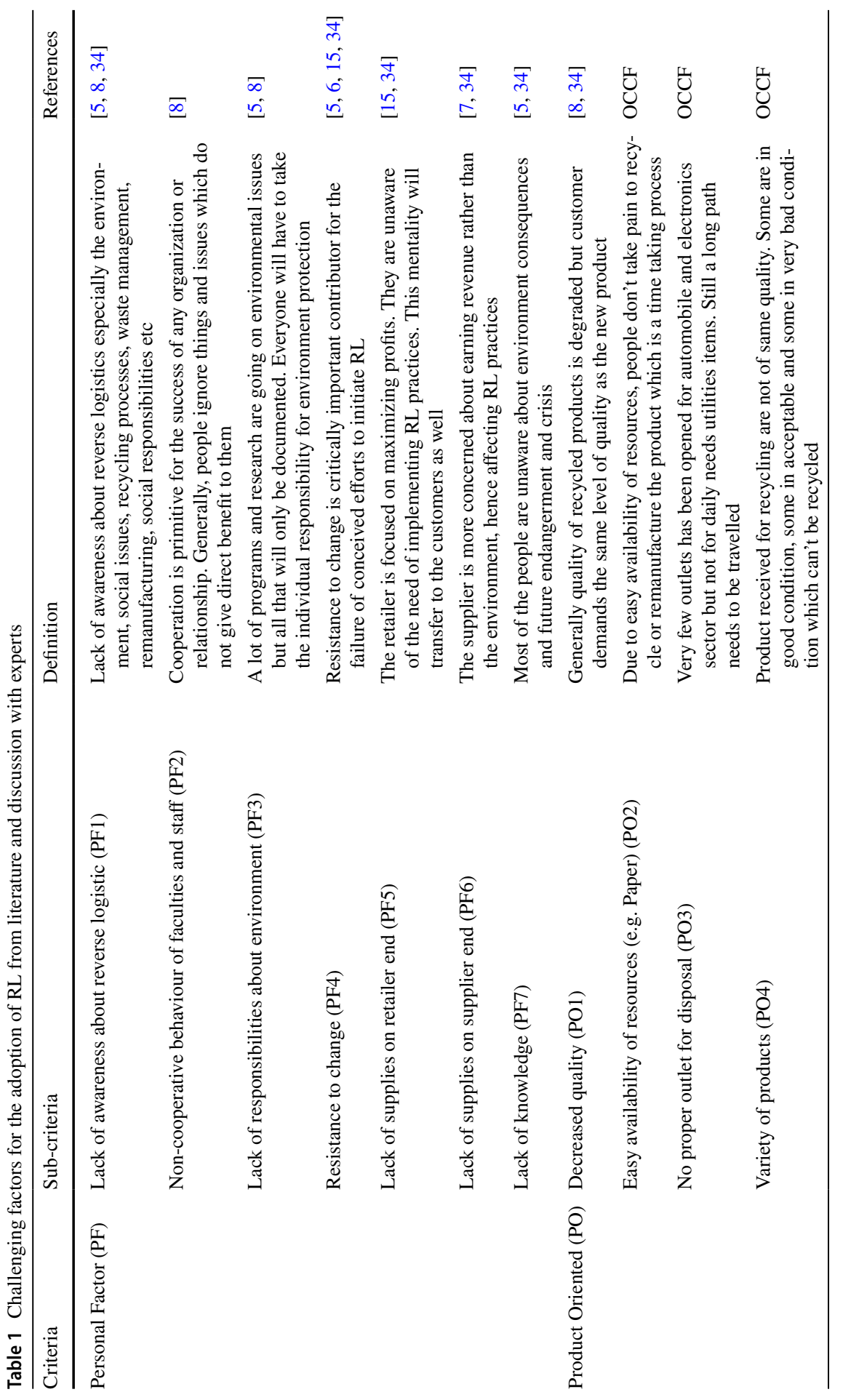




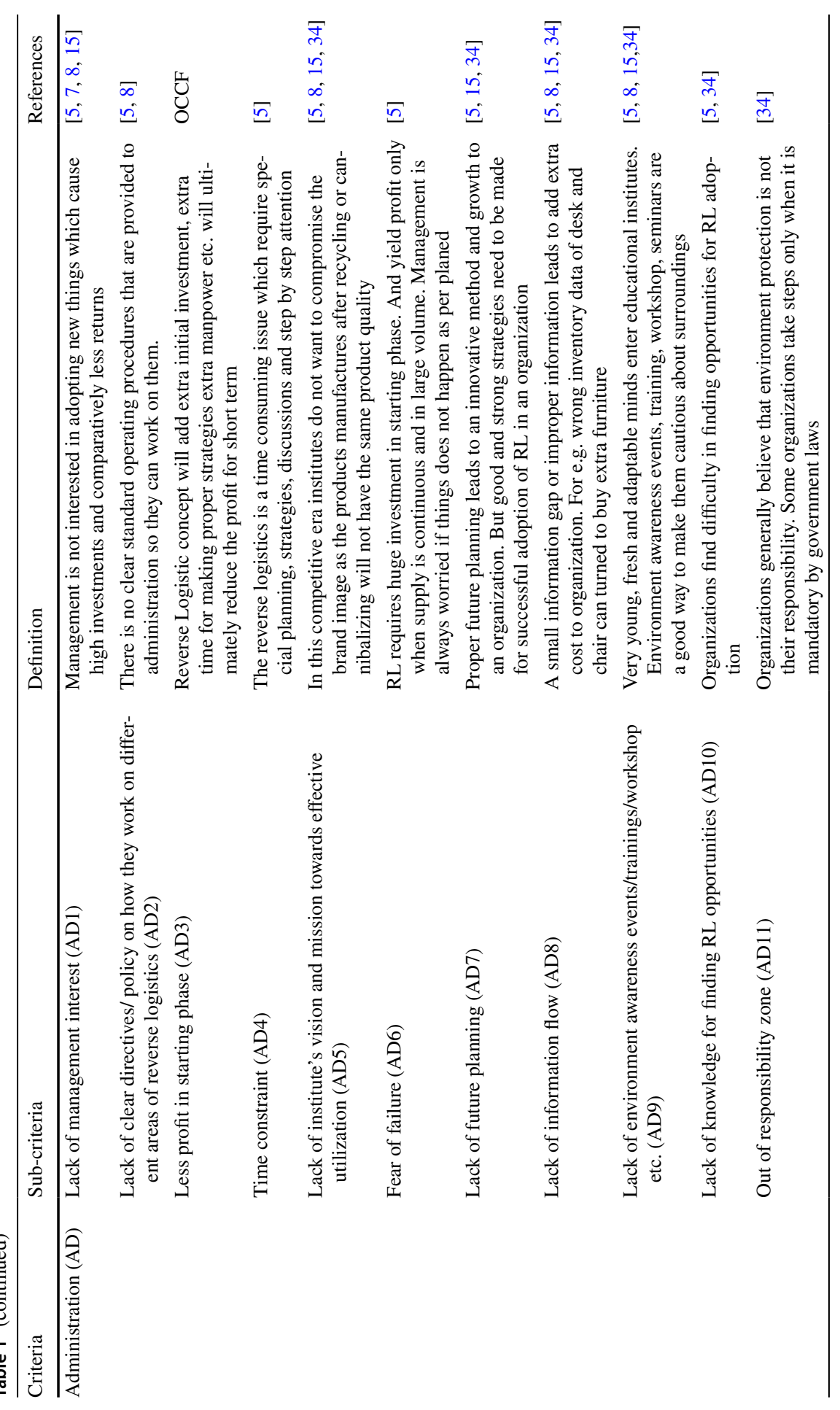




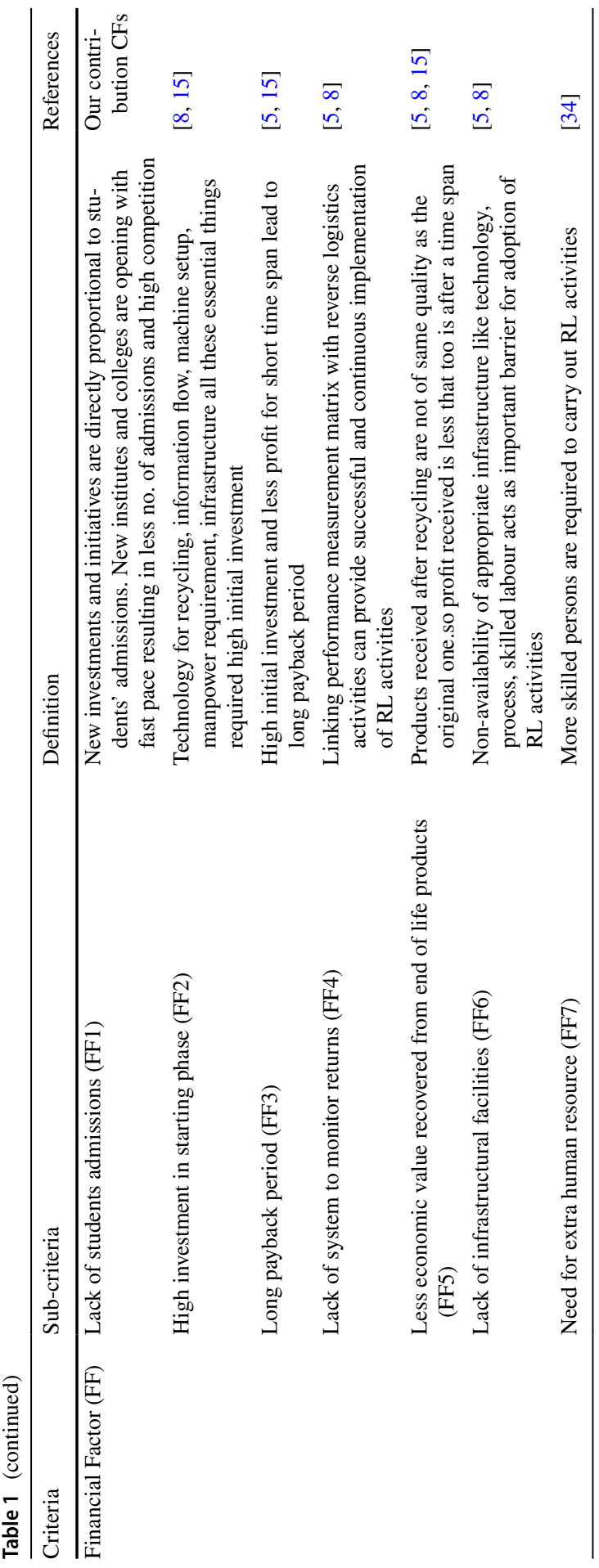




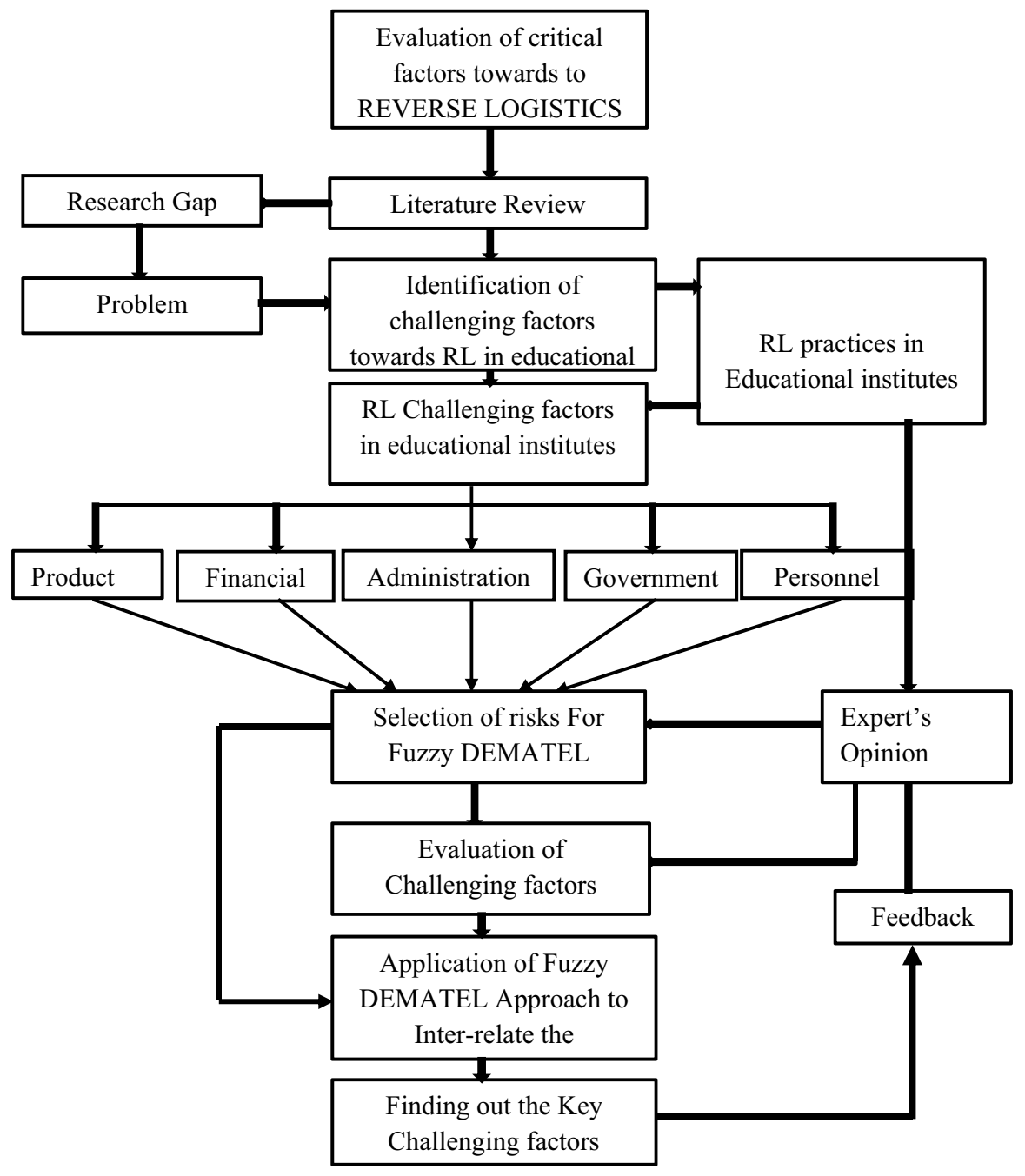

Fig. 2 Research methodology

\subsection{Fuzzy-DEMATEL}

DEMATEL is an advanced method for building a structural model for analyzing the interrelationship among complex factors. However, composing decisions is tough in fuzzy environments to divide the complex factors. Research scholars and RL practitioners consider how to manage enterprise operation more efficiently in a competitive market. An effective decision-making is crucial to handling RL operations. A study of the right and prominent challenges affecting RL operations would not only prove to be useful for existing RL practitioners, but also new entrants to the practice. Fuzzy-DEMATEL brings in the element of optimized decision-making to our 
Table 2 Quantification and fuzzification scale for linguistic response

\begin{tabular}{lll}
\hline Linguistic terms & $\begin{array}{l}\text { Influence } \\
\text { score }\end{array}$ & Triangular fuzzy numbers \\
\hline No influence (No) & 0 & $(0.0,0.0,0.25)$ \\
Very low influence (VL) & 1 & $(0.0,0.25,0.5)$ \\
Low influence (L) & 2 & $(0.25,0.0 .50,0.75)$ \\
High influence (H) & 3 & $(0.5,0.75,1.0)$ \\
Very high influence (VH) & 4 & $(0.75,1.0,1.0)$ \\
\hline
\end{tabular}

study. The tool accounts for the fuzziness in responses and provides a solid insight into the impacts the criteria on each other and ranks them in terms of prominence. It is understood that OR tools are typically applied to quantitative analysis. However, the ability of fuzzy-DEMATEL to optimize decision making for the purpose of our study gives it the edge it requires to be known as an operations research (OR) tool. The application of this tool in our study is therefore an addition for researchers towards advancing the operations research (OR) domain. Therefore, this qualitative study may also be referred to as an OR practice. The fuzzy-DEMATEL analysis procedure is explained step by step basis $[37,38]$.

1. Definitions of the challenges are identified through literature.

2. Pairwise comparison is done by experts which are integrated into educational systems using a linguistic scale: no influence; very low influence; low influence; high influence; very high influence.

3. Definition of the fuzzy linguistic scale is identified to account for the vagueness of human assessments. The five-level linguistic scale as proposed by $\mathrm{Li}$ is presented in Table 2 [39]. The table quantifies the linguistic scales and provides the fuzzy numbers for each 'influence' level. Convert these responses matrices with the help of scale $0-4$ in Table 2 to obtain quantified direct relationship matrices.

4. The initial direct relation matrix is obtained using the pairwise comparison done by the experts as indicated in Table 3. The fuzzy initial direct relationmatrix $Z^{\mathrm{k}}$ is developed with the introduction of fuzzy pairwise influence between the components of $n \times n$ matrix, where $\mathrm{k}$ is the number of respondents. The direct relation matric $\mathrm{Z}^{\mathrm{k}}$ is denoted as:

$$
\begin{gathered}
Z_{i j}^{k}=\left(l_{i j}, m_{i j}, u_{i j}\right) \\
Z^{k}=\begin{array}{ccc}
z_{11}^{k} & \ldots & z_{1 n}^{k} \\
\vdots & \ddots & \vdots \\
z_{n 1}^{k} & \ldots & z_{n n}^{k}
\end{array}
\end{gathered}
$$

5. The normalized fuzzy direct relation matrix - Table 4 denoted by $\mathrm{D}$ is obtained from the average fuzzy direct relation matrix $\mathrm{Z}$ using expression (2). 


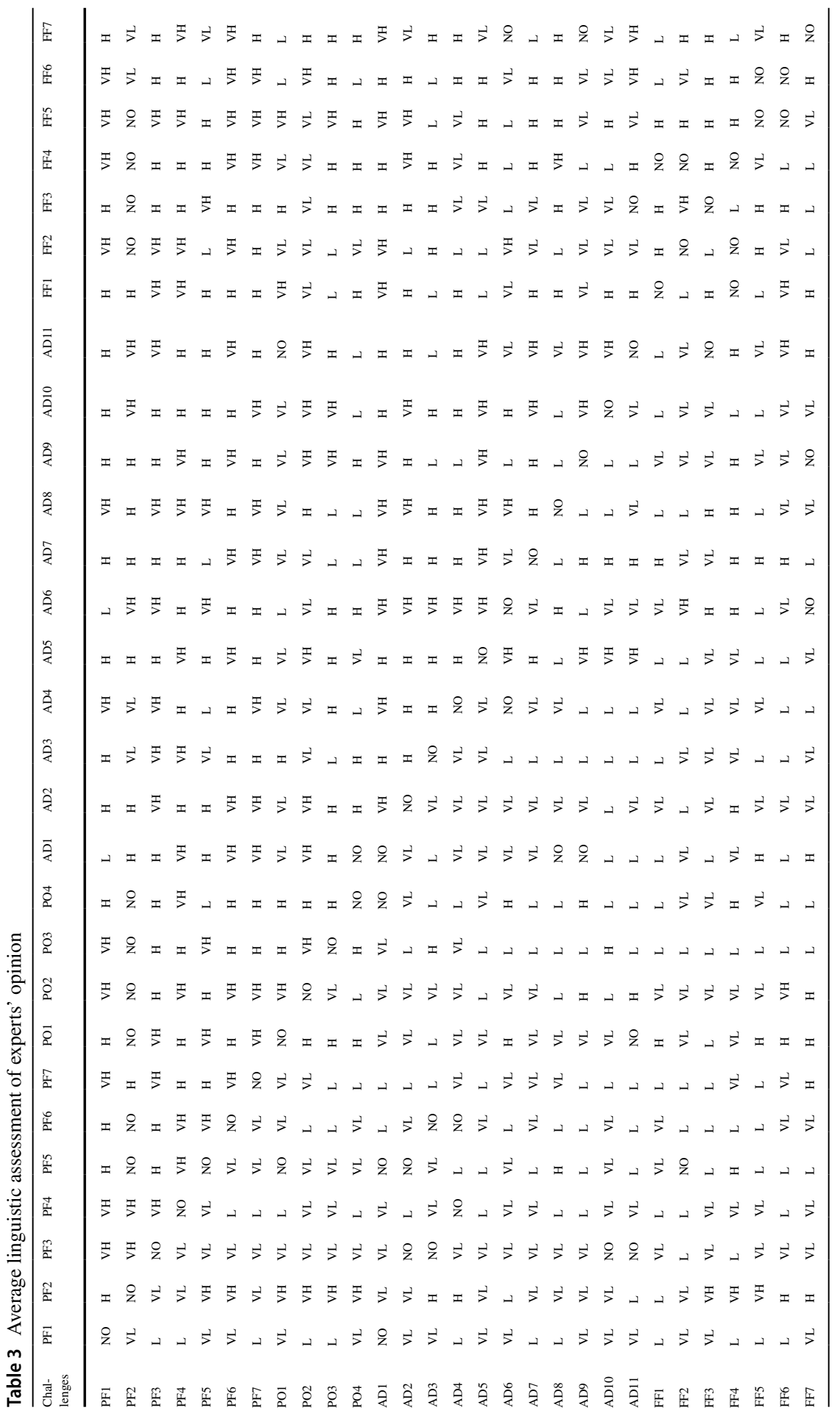




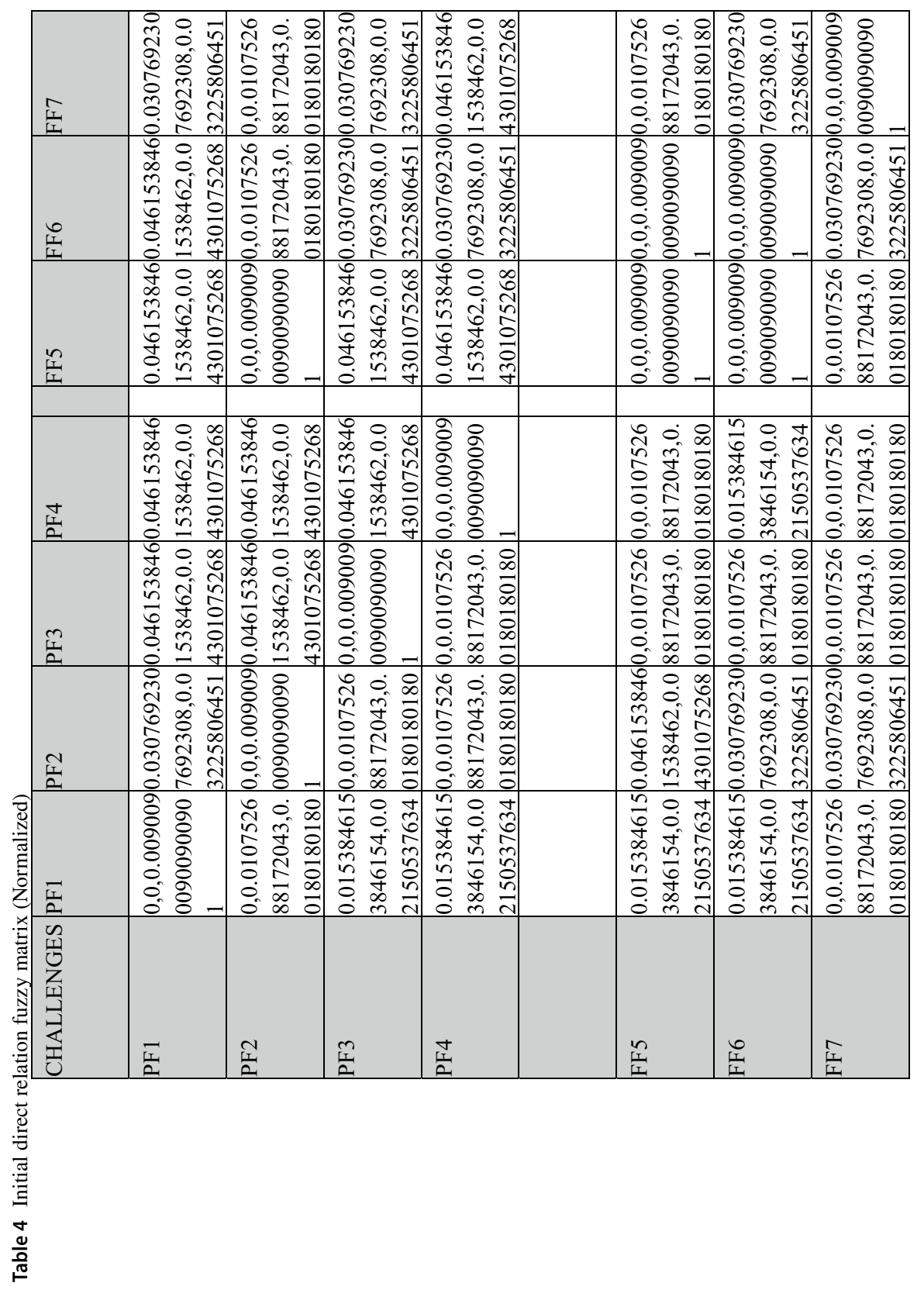




$$
D=\frac{Z^{k}}{\max _{0 \leq i \leq n} \sum_{j=1}^{n} Z_{i j}}
$$

6. Computation of the total relation matrix- Table 5 using the expression (3) given, where I represent the $\mathrm{n} \times \mathrm{n}$ identity matrix.

$$
T=D(I-D)^{-1} \quad \text { where } \quad T=D+D^{2}+\cdots+=\sum_{i=1}^{\infty} D^{i}
$$

7. Determination of the row sum $\left(r_{i}\right)$ and the column sum $\left(c_{j}\right)$ for each row $i$ and column $\mathrm{j}$ from the total relation matrix. The following equations are used to calculate the row and column sums.

$$
\begin{gathered}
T=\left[t_{i j}\right]_{n \times n} \quad \text { where } \mathrm{i}, \mathrm{j}=1,2 \ldots \mathrm{n} \\
r_{i}=\sum_{1 \leq j \leq n}^{n} t_{i j} \\
c_{j}=\sum_{1 \leq i \leq n}^{n} t_{i j}
\end{gathered}
$$

8. With the horizontal $\left(r_{i}+c_{j}\right)$ and vertical $\left(r_{i-} c_{j}\right)$ axes, the causal diagram is built. The horizontal axis represents factors that determine their 'prominence', meaning the importance degree of the factor. The vertical axis indicates the 'relation', that is the extent of the influence. The positive factors of $\left(r_{i-} c_{j}\right)$ axis fall under the cause group whereas the negative factors are in the effect group. The causal diagram converts the complex relationships of the challenges identified into a comprehendible structural model, hence providing awareness for problem-solving.

From the crisp values obtained in Table 7, a cause-effect diagram was drawn-Fig. 3.

\subsection{Data collection}

For this study, the experts targeted occupied administrative roles in various educational institutes in Kerala, India. Since the participants are decision-makers in their institution, the data collected is valid for this study. Table 8 gives a detailed profile of the 32 respondents. Before conducting this study, details about RL concepts along with the objective of this survey and how the data would be used were presented to ensure they understood the various questions in the questionnaire.

Phase 1: Identification of common challenges through an initial survey:

Given the choice of 'yes' or 'no' in this initial survey phase, the respondents were asked to identify the most important challenges out of the 45 challenges of RL adoption in their institute. The questionnaire was sent by mail to eight institutes and was followed up to ensure a quick response. The data to be entered by the respondents were linguistic and required the respondent to note the level of influence of one challenge with another. Out of the 32 respondents, 5 returned with incomplete data. This means the valid overall response rate was $84.37 \%$ which is well above the acceptable 20\% that Malhotra and Grover [40] suggested. 


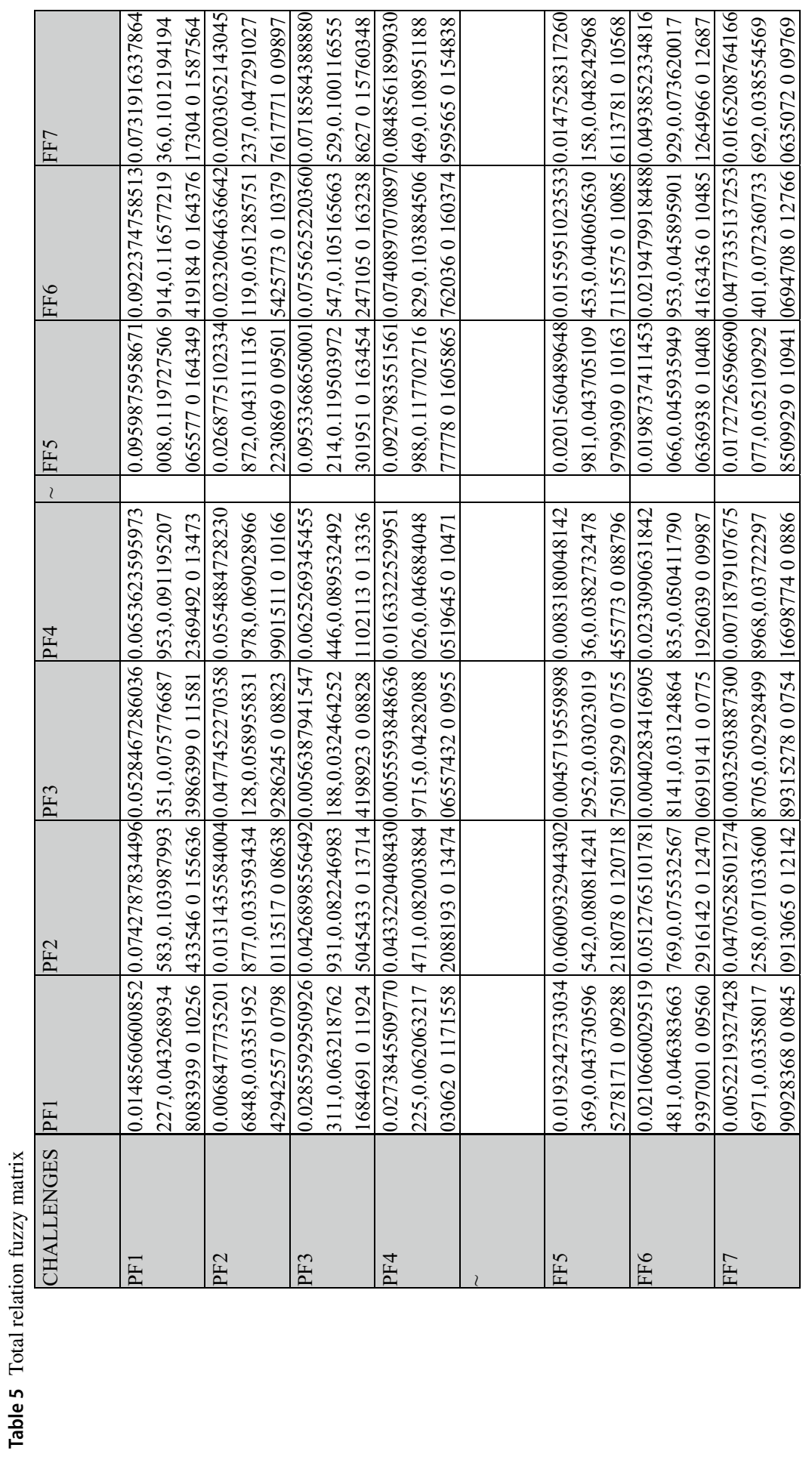




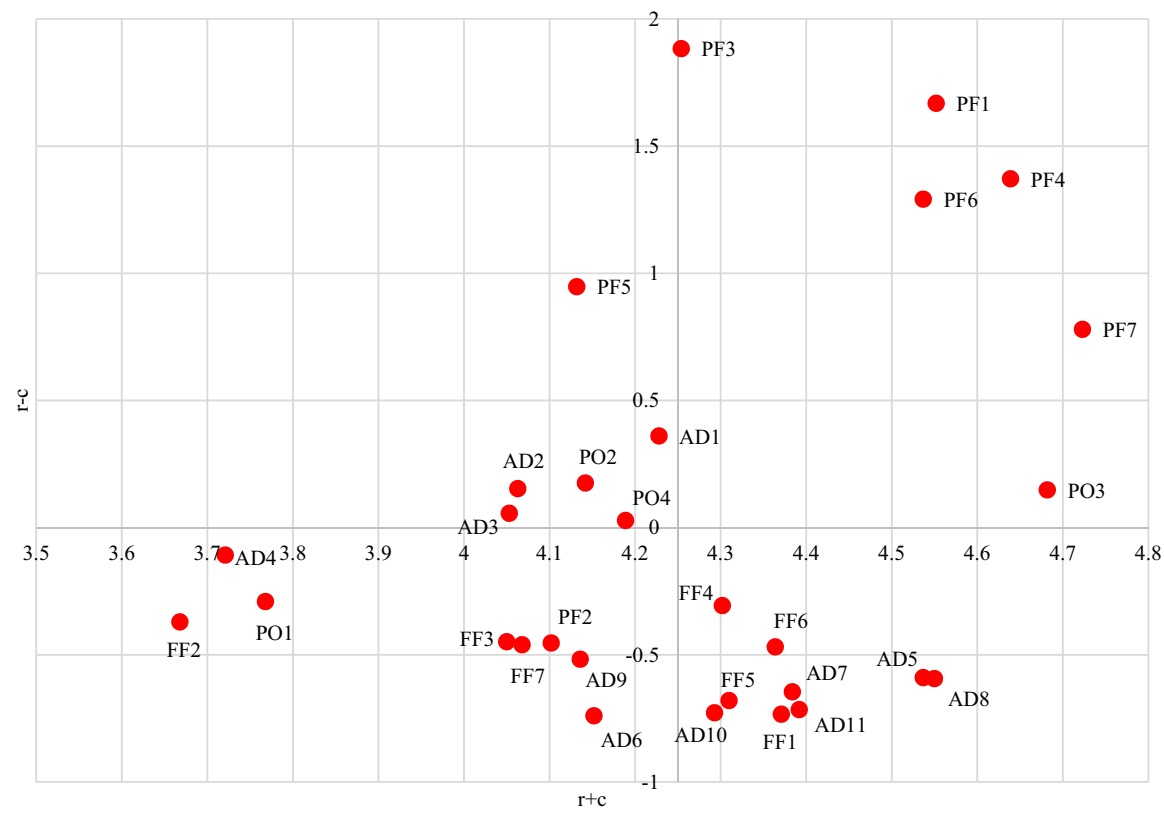

Fig. 3 Interactive relationship of the 29 challenges to adoption of reverse SCM in education institutions

Phase 2: Identification of the essential challenges:

Using the fuzzy-DEMATEL technique, the crucial challenges of RL adoption in education institutes were identified. At the end of the survey, 17 responses were received. The response rate is $53.13 \%$ and is acceptable for analysis [40]. The previous section gives details of the pair-wise comparison done along with calculations based on the response. The section that follows discusses the results obtained from the fuzzy DEMATEL methodology.

\section{Results and discussion}

The 29 challenges were characterized and presented according to relation $(\mathrm{r}-\mathrm{c})$ and prominence $(\mathrm{r}+\mathrm{c})$, as shown in Table 6 and Fig. 3. The challenges that have positive relation values are grouped as cause challenges. That is, these factors impact the whole system and affect the overall goal. In the context of this study, the cause challenges should be given attention because they affect RL implementation the most. The RL challenges that fall into the cause group include Lack of awareness about reverse logistic (PF1), Lack of responsibilities about environment (PF3), Resistance to change (PF4), Lack of supplies on Supplier end (PF6), Lack of knowledge (PF7), No proper outlet for disposal (PO3), Lack of supplies on retailer end (PF5), Lack of management interest (ADI), Lack of clear directives/ policy on how they work on different areas of reverse logistics (AD2), Less profit in starting phase (AD3), Easy availability of resources (PO2), and Variety of products (PO4). Amongst all the 


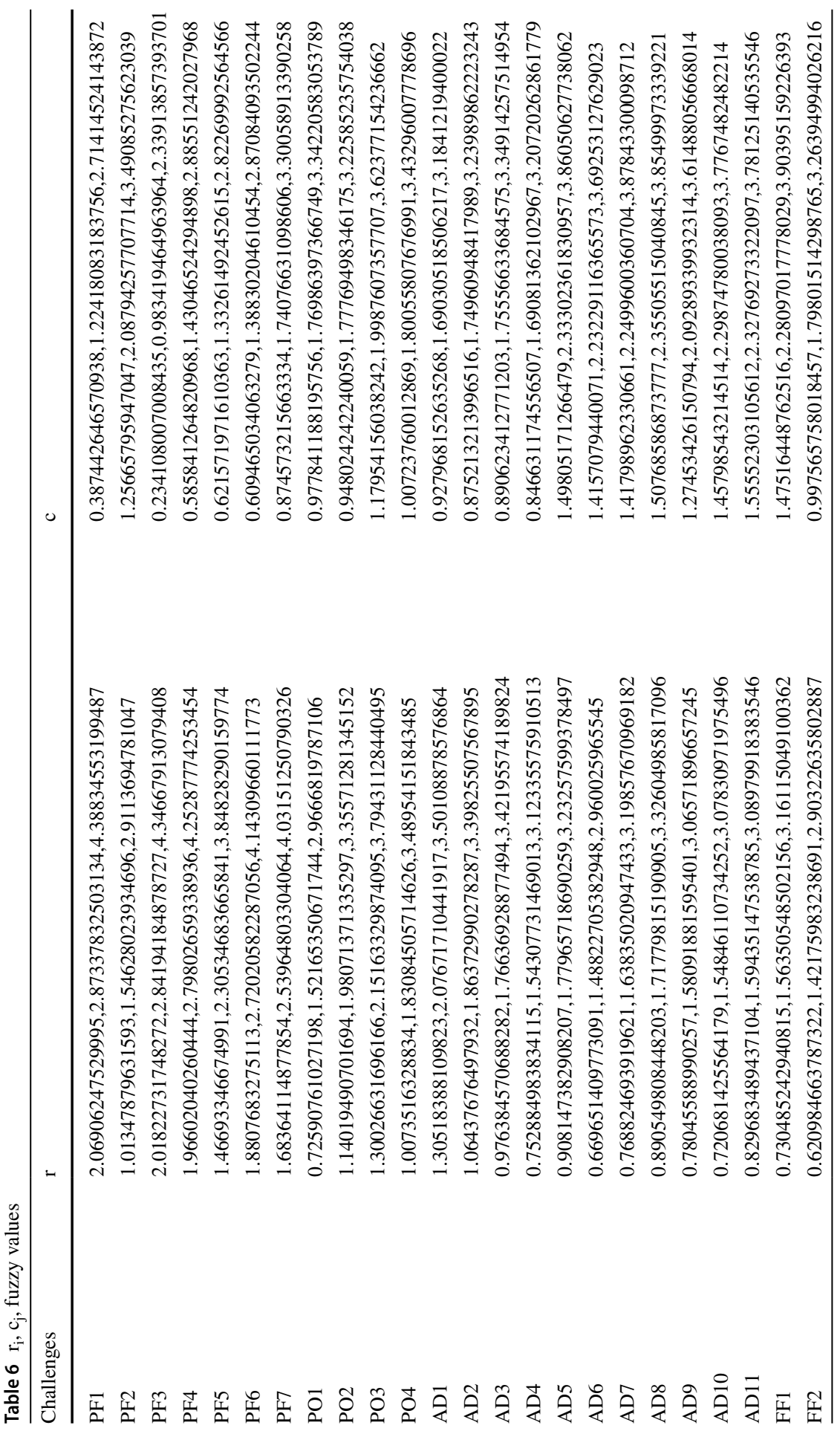




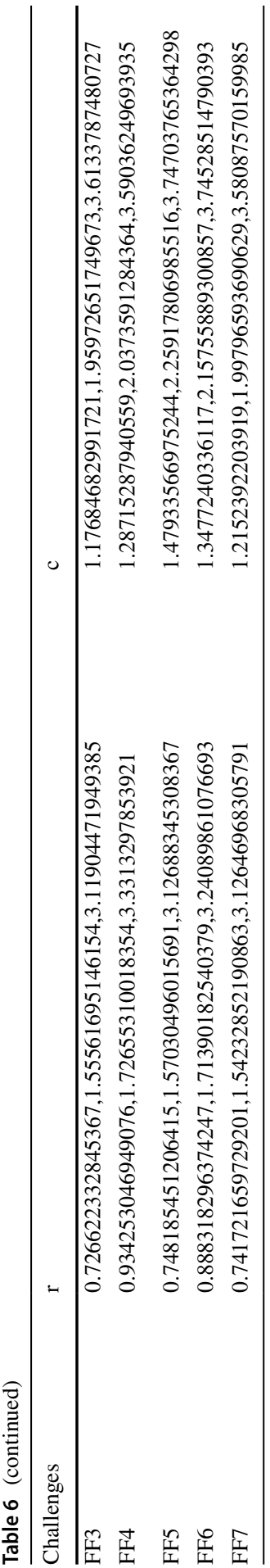


Table 7 Crisp values of ri, cj, $\mathrm{ri}+\mathrm{cj}, \mathrm{ri}-\mathrm{cj}$

\begin{tabular}{lllll}
\hline Challenges & $\mathrm{r}$ & $\mathrm{c}$ & $\mathrm{r}+\mathrm{c}$ & $\mathrm{r}-\mathrm{c}$ \\
\hline PF1 & 3.110262 & 1.441923 & 4.552185 & 1.668339 \\
PF2 & 1.82371 & 2.278484 & 4.102194 & -0.45477 \\
PF3 & 3.068949 & 1.185555 & 4.254505 & 1.883394 \\
PF4 & 3.005642 & 1.63394 & 4.639581 & 1.371702 \\
PF5 & 2.540188 & 1.592296 & 4.132483 & 0.947892 \\
PF6 & 2.91469 & 1.622869 & 4.53756 & 1.291821 \\
PF7 & 2.751601 & 1.971976 & 4.723577 & 0.779624 \\
PO1 & 1.738081 & 2.02997 & 3.768051 & -0.29189 \\
PO2 & 2.158874 & 1.983857 & 4.142731 & 0.175017 \\
PO3 & 2.415404 & 2.267358 & 4.682762 & 0.148046 \\
PO4 & 2.109246 & 2.080252 & 4.189498 & 0.028994 \\
AD1 & 2.29433 & 1.934132 & 4.228462 & 0.360198 \\
AD2 & 2.108787 & 1.954907 & 4.063694 & 0.15388 \\
AD3 & 2.054903 & 1.998444 & 4.053347 & 0.056459 \\
AD4 & 1.806439 & 1.914882 & 3.721322 & -0.10844 \\
AD5 & 1.97346 & 2.563861 & 4.537321 & -0.5904 \\
AD6 & 1.705968 & 2.446843 & 4.152812 & -0.74088 \\
AD7 & 1.868584 & 2.515461 & 4.384045 & -0.64688 \\
AD8 & 1.978133 & 2.57258 & 4.550713 & -0.59445 \\
AD9 & 1.809031 & 2.327436 & 4.136467 & -0.5184 \\
AD10 & 1.782484 & 2.51116 & 4.293645 & -0.72868 \\
AD11 & 1.837945 & 2.554822 & 4.392767 & -0.71688 \\
FF1 & 1.81838 & 2.553362 & 4.371742 & -0.73498 \\
FF2 & 1.648657 & 2.019844 & 3.668501 & -0.37119 \\
FF3 & 1.800428 & 2.249984 & 4.050412 & -0.44956 \\
FF4 & 1.997379 & 2.304958 & 4.302337 & -0.30758 \\
FF5 & 1.815125 & 2.495184 & 4.310308 & -0.68006 \\
FF6 & 1.947706 & 2.416856 & 4.364562 & -0.46915 \\
FF7 & 1.803507 & 2.264694 & 4.0682 & -0.46119 \\
\hline & & & & \\
& & & \\
PD & & & \\
& & &
\end{tabular}

Table 8 Profile of respondents from educational institutes

\begin{tabular}{lll}
\hline Profile & Total & Percentage (\%) \\
\hline Administrative Director & 2 & 6.25 \\
Dean & 3 & 9.375 \\
Head of Department & 5 & 15.625 \\
General Manager & 4 & 12.5 \\
Principal (Administration) & 6 & 18.75 \\
Human Resource & 9 & 28.125 \\
Transport Manager & 3 & 9.375 \\
Total & 32 & 100 \\
\hline
\end{tabular}


challenges in the cause group, Lack of responsibilities about the environment (PF3) has the highest (r-c) score with 1.88, meaning PF3 impacts RL implementation the most. Therefore, PF3 has a significant impact on other criteria. Following PF3, Lack of awareness about reverse logistic (PF1) has the highest $(\mathrm{r}-\mathrm{c})$ value of 1.67 . It can be noted that though Lack of knowledge ( $P F 7$ ) falls under the cause group with a value of 0.78 , it's $(r+c)$ is highest amongst the 29 challenges of the study. Showing importance to PF7 by negating it can greatly ease RL implementation. PF1, PF3, and PF7 are closely linked in that they fall under the personal criteria, meaning that while considering to implement RL in an educational institute, care must be given to address these challenges.

The challenges in the effect group tend to be easily affected by others. Out of the 17 challenges under the effect group, Lack of information flow (AD8) has the highest $(\mathrm{r}+\mathrm{c})$ value of 4.55 . This is because AD8 has a comparatively low r-value of 1.98 (degree of influential impact), and the c-value of 2.57 (degree of influenced) it exhibits is highest amongst all the challenges of this analysis.

The following points categorize the challenges into quadrants to better understand how Fig. 3 can be inferred:

- Challenges with high relation and high prominence: These challenges have a high relation and high prominence. This category comprised Lack of awareness about reverse logistic (PF1), Lack of responsibilities about environment (PF3), Resistance to change (PF4), Lack of supplies on Supplier end (PF6), Lack of knowledge (PF7), and No proper outlet for disposal (PO3). These challenges both highly influence RL implementation and affect the performance of the other factors.

- Challenges with high relation and low prominence: These challenges demonstrate high relation and low prominence. This category comprised Lack of supplies on retailer end (PF5), Lack of management interest (AD1), Lack of clear directives/ policy on how they work on different areas of reverse logistics (AD2), Less profit in starting phase (AD3), Easy availability of resources (PO2), Variety of products (PO4). These factors influence a minority of the other factors and the degree of influence is low.

- Challenges with low relation and high prominence: These challenges demonstrate low relation and high prominence. This category comprised Lack of Institute vision and mission towards effective utilization (AD5), Lack of future planning (AD7), Lack of information flow (AD8), Lack of knowledge for finding RL opportunities (AD10), Out of responsibility zone (AD11), Lack of students admissions (FF1), Lack of system to monitor returns (FF4), Less economic value recovered from end of life products (FF5), and Lack of infrastructural facilities (FF6). These factors are the result factors that are influenced by other factors, and cannot be directly improved.

- Challenges with low relation and low prominence: These challenges demonstrate low relation and low prominence. This category comprised Time constraint (AD4), Fear of failure (AD6), Lack of environment awareness events/trainings/ workshop etc. (AD9), High investment in starting phase (FF2), Long payback period (FF3), Need for extra human resource (FF7), Decreased quality (PO1), 
and Non-cooperative behavior of faculties and staff (PF2). These challenges are influenced by other challenges; however, the degree of influence is extremely low, suggesting that they are relatively independent.

To summarize the analysis aforementioned, the study reveals that education institutes need to focus on Lack of awareness about reverse logistic (PF1), Lack of responsibilities about environment (PF3), Resistance to change (PF4), Lack of supplies on Supplier end (PF6), Lack of knowledge (PF7), and No proper outlet for disposal $(P O 3)$. These factors are the reason factors, that is, they are the key challenges influencing other challenges, and are the main challenges that result in motivating the other challenges. The majority of focus needs to be given to the PF. Schools and universities can propose ways to educate the employees on the immediate and long term benefits of RL in the supply chain. It is evident that the world's resources are depleting and educating on the positive effects will help address these challenges. Educators can invest in researching this field to shed light on the purpose of adopting RL and implement it in their institutions. An awareness campaign through training and educating the need for environmental sustainability may be provided. Naeem and Welford and Moyeen and West [41, 42], similarly urge awareness through training, either formal or informal. Understandably, the adoption of RL comes with resistance to change. Counseling will help curb this resistance drastically. Once the benefits of RL is understood, educational institutes will show interest in its adoption. This will create a demand for supply from the suppliers' end. Furthermore, proper disposal methods need to be put into effect and focus must be put into it to have an effective recycling process. By emphasizing these criteria, educational institutions can achieve their goal of putting in place an effective RL system, thereby creating a greener supply chain. Also, to develop the RL process, a review of the returns handling terms may be established with vendors. This may sort issues from the suppliers' end.

The study may not be limited to a school supply chain, but also the supply chains of manufacturers and service industry alike. Though the empirical data collected are from educational institutes, it may be noted that the results presented are viable even in the case of manufacturers. Hossain et al. [43] revealed that stakeholders' understanding of environmental responsibility is limited to Corporate Social and Environmental Responsibility (CSER), and interviews conducted showed to prove that boards of directors of organizations do not appear to grasp the concept of CSER, and that it is not clearly defined or understood by stakeholder groups. It was suggested that a more genuine approach to CSER is to provide training programs and sustainability education for stakeholders and organizations.

\subsection{Theoretical framework}

The reverse logistics operations may be conducted under a why, how, what and who framework [3]. These four viewpoints are used to characterize the RL practice. For each process that exhibits potential for RL practice, these fundamental questions may be asked to analyze and implement an RL strategy. The 'why' answers the reasoning behind returning the item or product. The 'how' answers how the RL practice may 


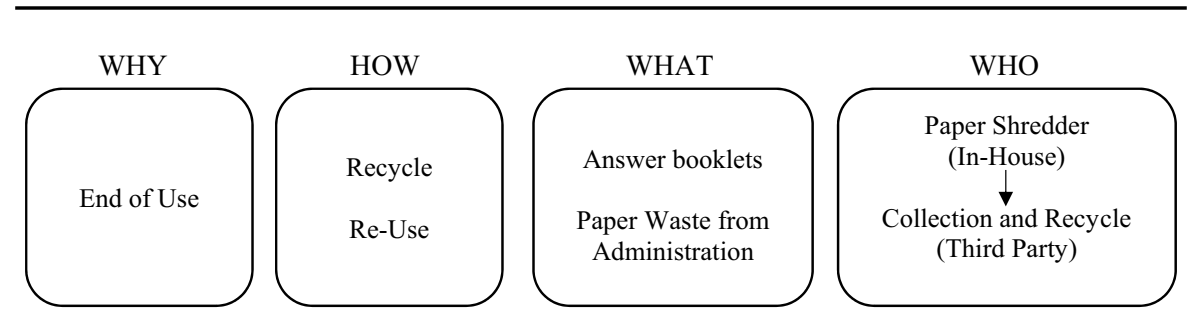

Fig. 4 Example framework application for campus paper waste

be undertaken, that is, the set of steps to undergo the RL practice, that is, how value is recovered. The 'what' defines and describes the item or product being returned, thereby determining the value of its re-use in the supply chain. The 'who' answers the identity of the practitioner of the RL process. This may be an internal actor or a third party. A simple working example of the framework is provided-Fig. 4.

\section{Conclusion and remarks}

For India to keep its economic growth rate on the rise, it needs to face the challenges of scarcity in the resource. Managing resource is important in a country like India that is on the verge of being the most populated country. The move towards adopting $\mathrm{RL}$ is not an easy one as it poses challenges on the way. This study reviews the critical factors towards RL from literature and discussions with experts from the educational institute located in Kerala. Twenty-nine influential factors critical to RL adoption are identified and analyzed using the fuzzy-DEMATEL approach. The data was collected through questionnaires distributed to various experts from the educational institute in Kerala. The analysis reveals factors that RL adopters need to focus on to avoid any impending challenges they may face. Major challenges that affect RL are lack of knowledge (PF7) and resistance to change (PF4) by the decision-makers and employees of the institute. This can be curbed by proper counseling to realize the necessity of RL to address the issue of resource scarcity in India.

Resource scarcity is a major problem in our country with over 1.2 billion in population. Decision-makers need to focus on adopting RL in their ventures. This study gives decision-makers who are ambitious towards achieving environmental sustainability the challenges that they may face in RL adoption and to find measures to avoid any possible preemptive challenges they may face in their educational institutions. Furthermore, in the eyes of society, institutes stand to gain a good reputation for being responsible. RL, if adopted successfully with consideration of possible challenges serves as a great marketing strategy resulting in increased intake of students who serve as the basis of income for education institutes.

\subsection{Managerial implications}

Our study provides insight into challenges faced by education institutions towards the adoption of reverse logistics. Our findings are obtained scientifically analyzed so 
that decision-makers can take this study to realize the major challenges, and make relevant decisions towards a socially, commercially and environmentally effective implementation of RL system in educational institutes. The major focus may be given to the PF as discussed in the results and discussion section. An effort needs to be made into educating the positive effects of adopting RL to the adopters. The RL implementation framework may be adopted by practitioners. It is simple, however, a major step towards reverse distribution planning.

The decision-makers may consider outsourcing their RL practices. Once the decision is made to outsource RL practices to a third party, it is irreversible. This is because once a strategy is chosen, it cannot be changed frequently. To focus on the decision to outsource, Serrato and Ryan [44] suggest that there are two possible actions (assuming RL practices are performed internally initially) in each period: either adjust internal capacity to match the expected number of returns in the next period, or switch permanently to outsourcing. The study will help managers of schools and universities in ensuring sustainable development through RL adoption in their campuses. Managers can make optimum decisions based on the challenges that have been identified and analyzed in this study to achieve operational and financial efficiency.

\subsection{Limitation and future scope}

This study is purely theoretical and is based on challenges identified through literature. A case study on the implementation of RL in an educational institution will further prove the validity of the challenges assessed in this study. Furthermore, this study could have been expanded to different states of the country rather than focusing on one. This study focused only on institutions residing in Kerala. Hence, more responses could have been obtained if the questionnaire was distributed among several other educational institutes.

\section{References}

1. Kumar Sharma, V., Chandna, P., Bhardwaj, A.: Green supply chain management related performance indicators in agro industry: a review. J. Clean. Prod. 141, 1194-1208 (2017). https://doi. org/10.1016/j.jclepro.2016.09.103

2. Tibben-Lembke, R.S.: Life after death: reverse logistics and the product life cycle. Int. J. Phys. Distrib. Logist. Manag. 32, 223-244 (2002). https://doi.org/10.1108/09600030210426548

3. de Brito, M.P., Dekker, R.: A Framework for reverse logistics. In: Reverse Logistics, pp. 3-27. Springer, Berlin Heidelberg (2004)

4. Rogers, D., Tibben-Lembke, R.: Going Backwards: Reverse Logistics Trends and Practices, vol. 2. (1999)

5. Kroon, L., Vrijens, G.: Returnable containers: an example of reverse logistics. Int. J. Phys. Distrib. Logist. Manag. 25, 56-68 (1995). https://doi.org/10.1108/09600039510083934

6. Corless, J., Ward, H.: Can brown be green? lessons from one university's quest for environmental responsibility. New Dir. High. Educ. 1992, 45-54 (1992). https://doi.org/10.1002/he.36919927707

7. Pandey, P., Govind, M.: Social repercussions of e-waste management in India: a study of three informal recycling sites in Delhi. Int. J. Environ. Stud. 71, 241-260 (2014). https://doi.org/10.1080/00207 233.2014.926160 
8. Prakash, C., Barua, M.K.: Integration of AHP-TOPSIS method for prioritizing the solutions of reverse logistics adoption to overcome its barriers under fuzzy environment. J. Manuf. Syst. 37, 599-615 (2015). https://doi.org/10.1016/j.jmsy.2015.03.001

9. Wooi, G.C., Zailani, S.: Green supply chain initiatives: investigation on the barriers in the context of SMEs in Malaysia. Int. Bus. Manag. 4, 20-27 (2014). https://doi.org/10.3923/ibm.2010.20.27

10. Govindan, K., Kaliyan, M., Kannan, D., Haq, A.N.: Barriers analysis for green supply chain management implementation in Indian industries using analytic hierarchy process. Int. J. Prod. Econ. 147, 555-568 (2014). https://doi.org/10.1016/j.ijpe.2013.08.018

11. Sharma, S.K., Panda, B.N., Mahapatra, S.S.: Analysis of barriers for reverse logistics: an Indian perspective. Int. J. Model. Optim. 1, 101-106 (2011)

12. Pohlen, T.L., Farris, M.T.: Reverse logistics in plastics recycling. Int. J. Phys. Distrib. Logist. Manag. 22, 35-47 (1992). https://doi.org/10.1108/09600039210022051

13. Lau, K.H., Wang, Y.: Reverse logistics in the electronic industry of China: a case study. Supply Chain Manag. 14, 447-465 (2009). https://doi.org/10.1108/13598540910995228

14. Rogers, D.S., Tibben-Lembke, R.: An examination of reverse logistics practices. J. Bus. Logist. 22, 129-148 (2001). https://doi.org/10.1002/j.2158-1592.2001.tb00007.x

15. Kannan, G., Pokharel, S., Sasi Kumar, P.: A hybrid approach using ISM and fuzzy TOPSIS for the selection of reverse logistics provider. Resour. Conserv. Recycl. 54, 28-36 (2009). https://doi. org/10.1016/j.resconrec.2009.06.004

16. Patil, S.K., Kant, R.: A fuzzy AHP-TOPSIS framework for ranking the solutions of Knowledge Management adoption in Supply Chain to overcome its barriers. Expert Syst. Appl. 41(2), 679-693 (2014). https://doi.org/10.1016/j.eswa.2013.07.093

17. Spekman, R., Werhane, P., Boyd, D.: Corporate social responsibility and global supply chain management: a normative perspective. SSRN Electron. J. (2005). https://doi.org/10.2139/ssrn.655223

18. Mudgal, R.K., Shankar, R., Talib, P., Raj, T.: Modelling the barriers of green supply chain practices: an Indian perspective. Int. J. Logist. Syst. Manag. 7, 81-107 (2010). https://doi.org/10.1504/IJLSM .2010 .033891

19. Efendigil, T., Önüt, S., Kongar, E.: A holistic approach for selecting a third-party reverse logistics provider in the presence of vagueness. Comput. Ind. Eng. 54, 269-287 (2008). https://doi. org/10.1016/j.cie.2007.07.009

20. Sarkis, J., Helms, M.M., Hervani, A.A.: Reverse logistics and social sustainability. Corp. Soc. Responsib. Environ. Manag. 17, 337-354 (2010). https://doi.org/10.1002/csr.220

21. Bouzon, M., Govindan, K., Rodriguez, C.M.T., Campos, L.M.S.: Identification and analysis of reverse logistics barriers using fuzzy Delphi method and AHP. Resour. Conserv. Recycl. 108, 182197 (2016). https://doi.org/10.1016/j.resconrec.2015.05.021

22. Jindal, A., Sangwan, K.S.: Development of an interpretive structural model of barriers to reverse logistics implementation in Indian industry. In: Glocalized Solutions for Sustainability in Manufacturing, pp. 448-453. Springer, Berlin Heidelberg (2011)

23. Prakash, C., Barua, M.K., Pandya, K.V.: Barriers analysis for reverse logistics implementation in indian electronics industry using fuzzy analytic hierarchy process. Procedia Soc. Behav. Sci. 189, 91-102 (2015). https://doi.org/10.1016/j.sbspro.2015.03.203

24. Samarasinghe, K., Haijun, W.: Challenges in implementing reverse logistics practices in Sri Lanka. Int. J. Inform. Bus. Manag. 11, 113-124 (2019)

25. Meade, L., Sarkis, J.: A conceptual model for selecting and evaluating third-party reverse logistics providers. Supply Chain Manag. An Int. J. 7, 283-295 (2002). https://doi.org/10.1108/1359854021 0447728

26. Bureau, E.: IMF forecasts $7.4 \%$ growth for India in FY19. https://economictimes.indiatimes.com/ news/economy/indicators/india-to-grow-at-7-4-per-cent-in-2018-imf/articleshow/62607671.cms

27. White, J.: Reverse logistics moves forward. Mod. Mater. Handl. 49, 29 (1994)

28. Blanchard, D.: Moving forward in reverse. trid.trb.org. 46 (2005)

29. Richey, R.G., Chen, H., Genchev, S.E., Daugherty, P.J.: Developing effective reverse logistics programs. Ind. Mark. Manag. 34, 830-840 (2005). https://doi.org/10.1016/j.indmarman.2005.01.003

30. Autry, C.W., Daugherty, P.J., Glenn Richey, R.: The challenge of reverse logistics in catalog retailing. Int. J. Phys. Distrib. Logist. Manag. 31, 26-37 (2001). https://doi.org/10.1108/0960003011 0366384

31. Andel, T.: Reverse logistics: a second chance to profit. Transp. Distrib. 38, 61 (1997) 
32. Tan, A.W.K., Yu, W.S., Arun, K.: Improving the performance of a computer company in supporting its reverse logistics operations in the Asia-Pacific region. Int. J. Phys. Distrib. Logist. Manag. 33, 59-74 (2003). https://doi.org/10.1108/09600030310461007

33. Stock, J., Speh, T., Shear, H.: Many happy (product) returns. https://hbr.org/2002/07/many-happy -product-returns

34. Economist, T.: Cash from trash. https://www.economist.com/business/1999/02/04/cash-from-trash

35. Carter, C.R., Ellram, L.M.: Reverse logistics: a review of the literature and framework for future investigation. J. Bus. Logist. 19, 85 (1998)

36. Dowlatshahi, S.: Developing a theory of reverse logistics. Interfaces (Providence). 30, 143-155 (2000). https://doi.org/10.1287/inte.30.3.143.11670

37. Akyuz, E., Celik, E.: A fuzzy DEMATEL method to evaluate critical operational hazards during gas freeing process in crude oil tankers. J. Loss Prev. Process Ind. 38, 243-253 (2015). https://doi. org/10.1016/j.jlp.2015.10.006

38. Seker, S., Zavadskas, E.: Application of fuzzy DEMATEL method for analyzing occupational risks on construction sites. Sustainability. 9, 2083 (2017). https://doi.org/10.3390/su9112083

39. Li, R.-J.: Fuzzy method in group decision making. Comput. Math. Appl. 38, 91-101 (1999). https:// doi.org/10.1016/S0898-1221(99)00172-8

40. Malhotra, M.K., Grover, V.: An assessment of survey research in POM: from constructs to theory. J. Oper. Manag. 16(4), 407-425 (1998)

41. Naeem, M.A., Welford, R.: A comparative study of corporate social responsibility in bangladesh and pakistan. Corp. Soc. Responsib. Environ. Manag. 16, 108-122 (2009). https://doi.org/10.1002/ csr. 185

42. Moyeen, A., West, B.: Promoting CSR to foster sustainable development: attitudes and perceptions of managers in a developing country. Asia-Pacific J. Bus. Adm. 6, 97-115 (2014). https://doi. org/10.1108/APJBA-05-2013-0036

43. Hossain, M.M., Alam, M., Hecimovic, A., Alamgir Hossain, M., Choudhury Lema, A.: Contributing barriers to corporate social and environmental responsibility practices in a developing country. Sustain. Accounting, Manag. Policy J. 7, 319-346 (2016). https://doi.org/10.1108/SAMPJ -09-2014-0056

44. Serrato, M.A., Ryan, S.M.: A markov decision model to evaluate outsourcing in reverse logistics. Taylor Fr. 45, 4289-4315 (2007). https://doi.org/10.1080/00207540701450161

Publisher's Note Springer Nature remains neutral with regard to jurisdictional claims in published maps and institutional affiliations.

\section{Affiliations}

\section{K. Mathiyazhagan ${ }^{1}$ (D) Srijit Krishnan ${ }^{1} \cdot$ Uma Bharathi $^{2} \cdot$ Andrea Appolloni $^{3,4}$}

K. Mathiyazhagan

madii1984@yahoo.com

1 Department of Mechanical Engineering, Amity School of Engineering and Technology, Amity University, Noida, Uttar Pradesh 201313, India

2 Department of Mechanical Engineering, The NorthCap University, Gurgaon, Haryana 122017, India

3 Department of Management and Law, Faculty of Economics, University of Rome Tor Vergata, Viale Columbia 2, 00133 Rome, Italy

4 Institute for Research on Innovation and Services for Development (IRISS), National Research Council (CNR), Via G. Sanfelice 8, 80134 Naples, Italy 